\title{
Smart Grid and Its Implications for Electricity Market Design
}

\author{
Seon Gu Kim ${ }^{\dagger}$, Seong Il Hur* and Yeoung-Jin Chae*
}

\begin{abstract}
Recently, smart grid has been considered a very important new energy delivery technology, and one that can help ensure a cleaner environment by making use of information and communication technology (ICT) in countries around the world. The many technological benefits smart grid offers is expected to bring about a huge change in the electric energy supply chain. In particular, smart grid with advanced ICT is likely to allow market agents to participate in the decision-making process in the restructured electricity industry, easily facilitating Homeostatic Utility Control. In this paper, we examine smart grid as a market externality, and then illustrate issues from the commercial market perspective as it relates to electricity market design. Finally, our paper identifies some of the impacts of smart grid on electricity market design, which may possibly be incorporated into the evolution of the electricity market, thus ensuring market efficiency.
\end{abstract}

Keywords: Smart Grid, Electricity Market, Quality of Supply, Market Externality, Information and Communication Technology

\section{Introduction}

We are in the midst of a rapidly and dramatically changing age from the perspective of electricity industry operation, as well as its extended global sustainability. There are two main issues creating many concerns in the electricity industry: Greenhouse Gas (GHG) emissions, and energy network modernization. Generally, smart grid is used as jargon to represent network modernization within the power system industry. These two issues are apparently independent of each other, although a careful look into them shows they are interestingly interlinked in order to achieve their designed goals. The background and the connection of these two issues are discussed in this introductory section.

Since first being reported a few of decades ago, the global climate change issue has emerged as a centerpiece of world-wide economic barriers, leading many countries to rush to expand their renewable energy initiatives, transforming their energy resource profile from a carbonintensive resource into a carbon-free resource when supplying electric energy. Although there are still many conflicts related to the climate issue among most countries at this point, it is expected that gas pollution reduction will be well coordinated to ensure it becomes a realty.

Meanwhile, many implementable measures are being considered to reduce gas emissions: carbon capture, clean development mechanisms (CDM), economic instruments (e.g. carbon tax and emission trading market), and direct control of fuel resources and end-user energy consumption. From the perspective of the electric energy supply chain, the most

$\uparrow$ Corresponding Author: Dept. of Information Technology, Korea Power Exchange, Korea (ksg9731@gmail.com)

* Dept. of Information Technology, Korea Power Exchange, Korea (ksg9731@gmail.com)

Received : September 7, 2009; Accepted : October 23, 2009 effective and close-linked way amongst the above gas reduction efforts is to control the usage of fuel resources and consumption by the end-user. For this purpose, as noted in [1], many jurisdictions are putting a huge amount of financial resources into the network modernization of the energy supply chain to facilitate smart grid, which is eventually aimed to reduce gas emissions by managing the energy flow between primary resources and the end-user in the process of supplying energy.

In this paper, we examine smart grid as a market externality and draw issues from the commercial market perspective for electricity market design. With these market externalities, our paper suggests market issues that may possibly be incorporated into on-going electricity market development, driving commercial arrangements toward greater efficiency.

\section{Smart Grid Vision}

As green technology becomes one of the most popular and important government policy tools to cope with the global economic recession as well as global climate change, smart grid has been placed as a top priority for the policy agenda of the national energy industry in countries around world. However, the concept and scope of smart grid are still very ambiguous, so many interested parties are seeing smart grid from a variety of differing perspectives.

In this section, the expectations of smart grid are discussed as it relates to energy delivery, and the jurisdictional context regarding what sort of new technological benefits might be incorporated into the commercialized electricity industry are explored.

\subsection{Newly Emerged Smart Grid for Socio-Sustainability}

Although its final feasible technology is not obvious, 
there is little doubt that ICT-based smart grid will necessitate changes in the way the electricity industry operates, eventually leading to a socio-sustainable society. The relationship between smart grid and socio-sustainability is shown in Fig. 1.

The ICT-based smart grid will be driven to cocoordinately achieve socio-sustainability mainly by facilitating energy efficiency, greater penetration of distributed energy resources (DER) and demand response in the process of electric energy supply. As a result, the dependency of conventional carbon-intensive fuels might be reduced by curtailing the consumption of coal-fired fuel, fostering an environmentally sustainable society through gas emission reduction.

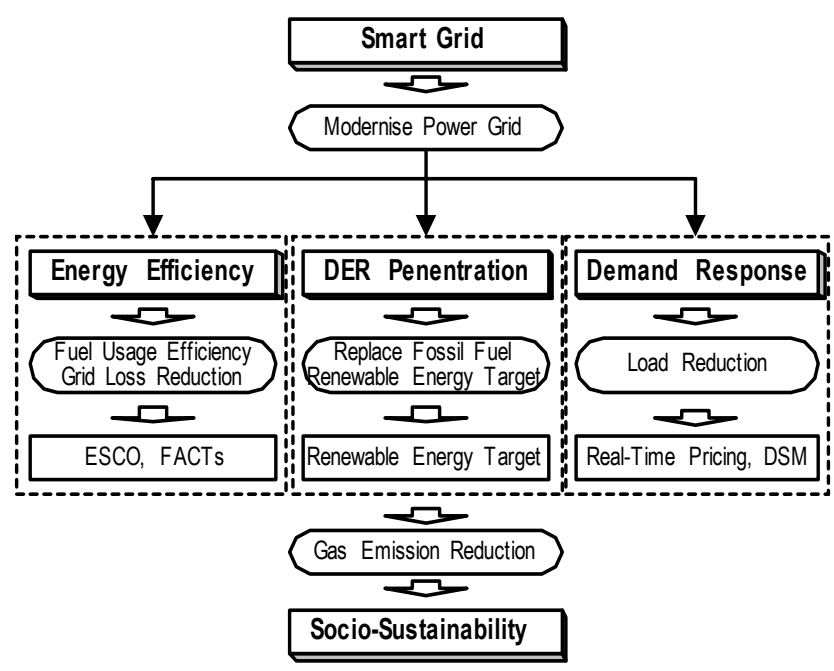

Fig. 1. Smart Grid Technology Vision for Socio-Sustainability.

\subsection{Smart Grid Vision from an Energy Supply Chain Context}

Implementing methods or technology to facilitate sociosustainability might obviously be different depending on the energy delivery context as well as the jurisdictional context, since the available technology and political targets with respect to smart grid are different, respectively.

(1) Energy Generation Sector: The most plausible expectation within the generation sector is to replace conventional carbon-intensive resources with carbon-reduced renewable resources such as solar, wind power and hydro. However, the replacement and penetration of renewable resources is obviously dependent on environmental, national and international policies. In addition, carbon capture technology is another technology expected to be developed to realize ICT-based smart grid in the generation sector.

(2) Transmission Sector: The main role of the transmission sector is to deliver a huge amount of electric energy in a reliable and efficient manner from the primary resource to the distribution point. Flexible Alternating Current Transmission Systems (FACTS) devices are considered to account for energy efficiency by reducing transmission losses by means of manipulating energy flow. Also, timesynchronized phasor measurement units (PMU) might be applied to enhance reliability by utilizing advanced monitoring applications.

(3) Distribution Sector: Since smart grid has emerged as a new technical motivation, much attention has been paid to the distribution network rather than the transmission sector. Given that renewable energy penetration is the main driving impetus for counterattacking the climate change issue in the USA and Europe, it would be very important to technically and commercially manage the appropriate measures for embedding renewable resources into the distribution network through ICT-based smart grid as much as possible. Likewise with transmission control, distribution management systems (DMS) are another key technology to embrace and operate in the smart grid-based modernized distribution network.

(4) Energy End-Use Sector: The distinguishable change from the conventional customer sector is to transform it from a unidirectional supply to a bidirectional supply, so that electric energy could be interlinked between the supplier and consumer. As with the Internet, energynet will become the common energy infrastructure in the era of the smart grid-based electricity industry in the energy end-use sector. Thus, the technological philosophy of the end-use sector is to replace the conventional concept of 'Slave Follows Master' with that of 'Homeostatic Utility Control (HUC)' [12]-[13], which was suggested as a conceptual and revolutionary vision of the deregulated electricity industry when the industry began restructuring. Unfortunately, HUC is not fully implemented in most electricity market places due to technical limitations.

\subsection{Smart Grid Vision from the Jurisdictional Context}

In this section, a few countries' policy and vision for smart grid is explored to briefly assess which technical scope will be most feasible after smart grid is achieved, and as planned in the respective jurisdictions.

(1) USA: Newly emerged industry issues such as global climate and power system blackouts have driven the power system network into intellectualization in two ways in North America. Firstly, network modernization was already launched and researched as the IntelliGrid Project at the EPRI to transform the electric energy network into a very highly automated, responsive, and resilient power delivery system by integrating electricity with both communication and computer control technologies [2]. After the Energy Independence and Security Act of 2007 (HR6) was passed, smart grid as an extensive alternative approach is being managed by the DOE to achieve reliability, efficiency, flexibility and security in delivering electric energy by means of integrating information technology into the electric network. 
In addition to network modernization, another big goal of Smart Grid in the USA is to voluntarily engage the demand sector into the chain of power energy delivery. Demand side engagement is usually projected by demand side management (DSM), which usually embraces the demand response tool as well as energy efficiency in the USA [9]. A huge amount of financial resources are supposed to enhance the energy efficiency of demand side engagement within the economic stimulus scheme implemented by Obama's administration.

(2) Europe: SmartGrid's European Technology Platform, ETP-SmartGrids, for the future electricity network commenced in 2005, and its aim is to formulate and promote a vision for the development of Europe's electricity networks looking towards 2020 and beyond [3], and more detailed research strategies are developed to drive the European smart grid vision into reality [4]. The highlight of the European smart grid initiative is to mainly accommodate more decentralized generation services, with many players involved in the generation, transmission, distribution and operation of the system, whilst the centralized generation and high voltage bulk-transmission of electricity will continue to play a major role for the foreseeable future [5]. As a result, Europe's electricity network in 2020 and beyond will be flexible, accessible, reliable and economic. Currently, Europe is developing a strategic deployment priority.

(3) Australia: In its vision statements, Smart Grid Australia, which recently allied with multi-parties in 2007, is no doubt seeking Smart Grid solutions to achieve energy efficiency and climate change [6]. To meet the proposed aims, Smart Grid has developed to address an energy efficient and environment-friendly transformed society by means of innovative information technologies. In particular, Smart grid Australia intends to make the energy end-user take part in establishing an energy transformed society through demand participation. In fact, Smart Grid Australia has just begun to support the industry as it transitions into an energy transformed society by implementing the following areas: smart grid standards, advanced metering infrastructure (AMI), development of an emission trading scheme (ETS), industry transition to smart grid, and smart grid communication infrastructure. Consequently, unlike the USA and Europe, smart grid in Australia has been initiated only to achieve demand side engagement at the current evolving stage.

(4) China: Unlike the direction of the leading developed countries, China is likely to take a very different approach to developing and adopting smart grid technologies. As $\mathrm{Hu}$ Xuehao of the China Electric Power Research Institute pointed out [7], Chinese smart grid will be emphasized on the transmission grid rather than the distribution grid, which many western countries focused on. For example, the 'West-East Electricity Transfer Project' included in the unified national power grid project, which aims to finish the creation of an integrated national grid by 2020 , thereby increasing energy delivery efficiency across the national transmission grid [8]. Moreover, a series of contracts such as a high voltage DC (HVDC) transmission link and an
$800 \mathrm{KV}$ ultra high voltage DC system between Chinese transmission companies and global energy vendors demonstrates the Chinese smart grid vision for transmission system modernization.

From the discussion above, it is not easy to deterministically define the technological scope of smart grid. Nevertheless, the most visible and plausible technical boundary is very likely the end-user's engagement and increased penetration of renewable resources in the end-user sector of the energy supply chain. So our discussion will focus on the end-user sector of smart grid in the remaining sections.

\section{Market Design and Externalities}

In this section, we will look into the basic arrangements of the conventional electricity market from the design perspective. Then, the expected market externalities to be incorporated into the smart grid-based electricity industry are discussed in order to identify the missing links or flaws of the current market regime in the next section.

\subsection{Market Design}

We have observed institutional restructuring and commercial operation in the world's electricity industry over the last few decades. The centerpiece of electricity restructuring is that electric energy resources, the transportation network and demand-side electrical equipment including technical and operational constraints are given, and then decision-making to maximize social benefits is transformed from a centralized engineering optimization problem into a decentralized commercial optimization problem [9]. However, since there are no cost-effective storage devices for electric energy and thus supply and demand must be instantaneously balanced, technical and security decision-making is centralized to deliver electricity from supply to demand as an uninterrupted single function, whereas the decision-making for the commercial arrangement is fully decentralized to maximize economic efficiency in the designer's market. The generic structure of market-based restructured electricity is shown in Fig. 2.

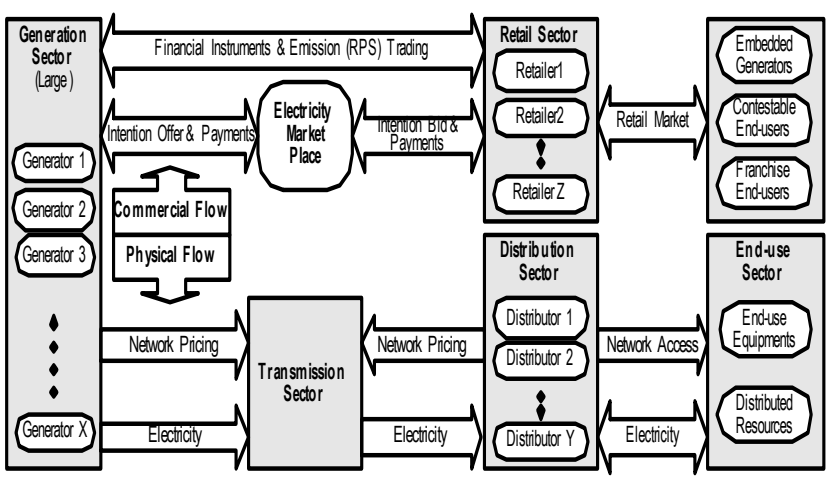

Fig. 2. Generic Structure of Restructured Electricity Industry (Reproduced based on [9]). 
In most well-formed global electricity markets such as Australia, Norway, England and Wales and North America, energy supply is only commercialized between the generator and distribution, whereas retail end-users, except large eligible customers, are still franchised to consume energy, and thus the energy cost is allocated to users by using a conventional ToU (Time of Use) tariff. In the commercialized sector, allocation efficiency is achieved for market participants by means of more-centralized decision-making commercial arrangements such as an inter-temporal price discovery mechanism as well as financial instruments. Meanwhile, network services between the supplier and consumer are monopolized and regulated to allocate cost.

\subsection{Market Externalities}

As we discussed above, the ultimate destination of the smart grid is to achieve greater socio-sustainability. Thus, it would be more appropriate to characterize factors which might affect the current commercial regime or arrangement when the industry is transformed from the conventional electricity industry to a socio-sustainable industry with the help of smart grid as well as other policy instruments.

In Fig. 3, two market externalities are mainly characterized as the electricity industry is transformed into becoming socio-sustainable in the future: global warming externality, and the information technology industry

Firstly, environmental constraint to reduce gas emissions is an impetus to exploit the advantages of smart grid technology. The reliance on emission-free resources, which will be driven by limiting permission to emit gases, will drive the electric energy supplier to greater exposure to cost increases, leading to investment in cost-intensive renewable energy. For example, a generation company located in Australia failed to refinance its debt and cancelled its planned annual overhaul maintenance, after the bank became wary of the impact of looming Australian Carbon Pollution Reduction Scheme (CPRS) [10]. This meant that the global warming externality has already become a reality in the electricity industry.

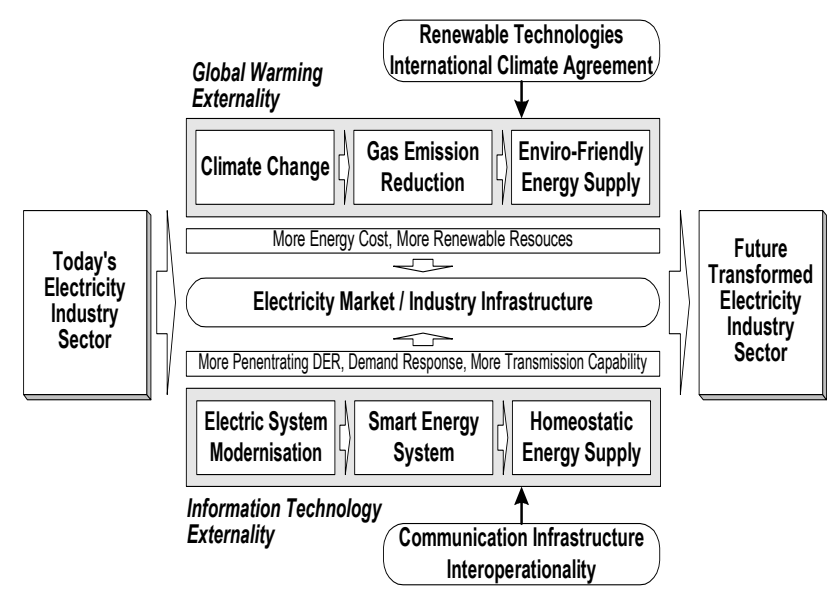

Fig. 3. Characterization of Externalities into Restructured Electricity Industry.

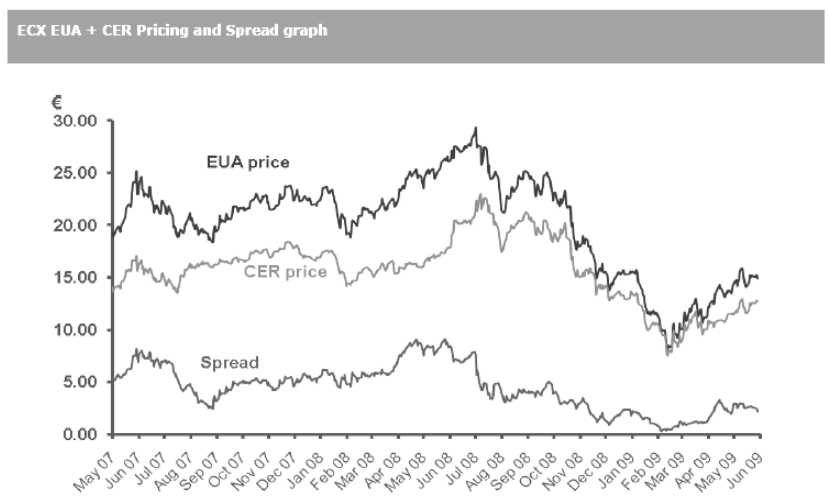

Fig. 4. EUA and CER Price [Source: www.ecx.eu].

Secondly, advanced technologies in both telecommunications and computing might also play an important role in externality on the electricity industry. In particular, information embedded in energy flow might be greatly expanded in quantity as well as extended in its communicated scope. From the market perspective, the most obviously expected benefit to be contributed by introducing smart grid is the change of information flow from a unilateral flow into a bilateral flow, and the possibility of a more decentralized decision-making process. In addition, more high speed computing will allow a reduction in the decision resolution period in the inter-temporal decisionmaking process.

\section{Market Design Incorporating Smart Grid Technology}

We have discussed energy sustainability and the progress status of smart grid technology in the previous sections. In this section, we will discuss and suggest ways to incorporate new smart grid technology into the commercialized electricity industry in terms of market design.

\subsection{Scope of Discussion}

As discussed, the influential scope and objective of smart grid is very different from the perspective of jurisdiction and industry sector. Moreover, it is also unclear how the technical vision of smart grid will be achieved within the planned timeline. Thus, the scope of discussion should be assumed as follows.

Since global efforts are placed on energy sustainability and global warming, it is observed that most of the released smart grid visions commonly include the incorporation of distributed resources into the energy supply chain. In fact, a huge amount of financial resources are planned to be invested in the utilization of distributed resources, including renewable resources in the USA and Europe. Concurrently, jurisdictional regulators plan to reduce energy intensive generation expansion by replacing new generation investment with the reduction of energy consumption at the 
end-user. The representative policy instrument for energy consumption reduction is demand response (DR), which might spread energy consumption and thus reduce the energy supply margin.

Thus, taking into account the huge efforts to manage this distributed resource, such as distributed energy resource (DER) and demand control resource (DCR), it is expected that the end-user sector rather than the generation and transportation sector will adopt the new advanced technology as planned, and therefore many changes could be expected from the electricity market design perspective. Accordingly, our interests will focus on the end-user sector to discuss the impacts of smart grid technology on electricity market design.

\subsection{Smart Grid Impacts on Market Design}

The decision-making framework of the modern electricity industry consists of a governance regime, security regime, technical regime and commercial regime [11]. Given that the final destination of smart grid is to be used as an implementable tool to efficiently achieve a transformed energy industry by allowing it to either intake greater distributed energy resources or utilize its demand control resources (demand response), it is very important that a more coordinated and decentralized arrangement for the operation and investment of distributed resources be achieved in order to deliver net social benefits [11]. In addition, the bidirectional energy flow provided by smart grid between the supply and demand would be likely to highlight the operational environment of Homeostatic Utility Control in the electricity industry of the future. The conceptual philosophy of operating the electricity market incorporated by distributed resources stems from the Homeostatic Utility Control (HUC) [12]-[13].

Moreover, smart grid would penetrate distributed resources such as distributed energy resources and demand control resources into the industry-wide power system, bringing changes to the decision-making frame of the existing electricity industry. Also, the expected changes in the electricity industry, operated by Homeostatic Utility Control on the basis of smart grid technology, are briefly discussed below from the perspective of four fundamental regimes.

\section{(1) Impacts on Market Governance Regime}

Firstly, given that the role of the retailer is not clear or obscure even in the current competitive retail market, the function of the retailer is expected to expand, leading to the creation of a new market player between the distribution network service provider (DNSP) and the consumer. For example, as Thomas Friedman and Hugh Outhred illustrated in $[11,14]$, an Energy Service Company (ESCO) will have more influential functionality in the electric energy supply chain from the consumer's perspective in the electricity industry. Likewise, many other unprecedented types of market players might become embedded in the electricity market, which would require the re-design of regulatory institutions. Secondly, the emergence of many new market players will require regulatory changes between regulators and distribution network service providers to ensure fair and transparent network access. Thirdly, both technical and commercial arrangements of network interconnection are expected to change in order to efficiently allocate proper authority and accountability.

\section{(2) Impacts on Security Regime}

Firstly, taking into account the fact that most distributed energy resources (DER) are characterized as intermittent resources and are very small in size, it becomes a very critical issue for DER to equip themselves with ridethrough capability in the event of system disturbance. Secondly, since the HUC might frequently bring about a demand control by shedding customer load via commercial contracts, it is also important for power systems to accommodate load shedding capabilities in the event of demand controls. Finally, on top of both the ride-through and load shedding capability, electric power has to be secured from the stability perspective at the post disturbance point. Thus, an automatic centralized control management, e.g. multiple and distributed energy management system (DMS), is needed to operate and secure the electric energy supply.

\section{(3) Impacts on Technical Regime}

Firstly, the technical standard of the inter-operation communication protocol between smart grid devices is inevitable in order to be effective in the bi-directional energy flow. For this effort, IEC is operating a few technical committees to establish a common protocol for inter-operation [15]. Secondly, much attention has to be focused on the technical requirement of the distribution network grid accessed by intermittent DER. For example, the technical requirement of the ride-through capability for wind power generation has gradually demanded a more robust and uninterrupted energy supply in some jurisdictions. Thirdly, given that electric equipment at the energy consumer end is designed to operate within pre-determined requirements of quality of supply (QoS), it is also critical to properly set up and coordinate QoS-related standards. A high penetration of intermittent DER will deteriorate the QoS of electric energy supplied to consumers. Finally, greater technical efficiency will be expected by utilizing technical innovations in the electricity industry. For example, electronic devices which could interact with the energy flow in a network grid are likely to be embedded in electrical equipment to optimize the usage of energy consumption. This would require additional technical standards to accommodate the technical benefits into the actual energy supply chain of the electricity industry.

\section{(4) Impacts on Commercial Regime}

Obviously, the two-way communication capabilities em- 
bedded into the power system by smart grid have huge implications for firms, markets, and consumers. In particular, the most important aspect will be the effect on the transaction costs of utility companies. High transaction costs have been one of the most powerful rationales for vertical integration in the electricity industry for a century the world over. However, the bi-directional information exchange and decentralized control in smart grid would make it possible to lower the transaction costs and will make transactions in markets more attractive than ever, a fact that will surely contribute to the robust expansion of the wholesale and retail electricity markets [18].

Meanwhile, the commercial arrangement for trading electricity will likely change as follows. Firstly, it is quite obvious that some sort of commercial arrangement is needed to efficiently evaluate the contribution of distributed resource in terms of energy provision as well as managing the quality of supply. In particular, since a huge number of suppliers and consumers are widely dispersed in the distribution network, the regime of conventional centralized ancillary services will not be appropriate to maximize allocation efficiencies. For example, as the author et al suggested in [16], a more advanced and decentralized commercial market model is likely necessary to manage the voltage problem in a HUC-based restructured electricity industry. Secondly, it is also necessary to operate forward looking financial instruments to provide DER investors a risk hedge of revenue. Otherwise, Quality of Supply service providers will not have the incentives to invest in QoS-related resources, leading to degrading energy quality. As illustrated in [17], the Quality of Supply premium is a good example of a financial tool to drive the investment of QoS resources. Moreover, a commercial regime for the risk hedge is needed to consider the allocated efficiency between the physical supply and financial instruments. Finally, the financial support regime will be considerable and will drive DER and DCR to making investments if the economic regime is not applied depending on geological and environmental barriers.

\section{Closing Remarks and Visions}

Even though it is not clear where and how this smart grid vision will evolve in the future, it is obvious that smart grid based on advanced telecommunications and computing techniques would influence restructured electricity industry. In this informative paper, the implications of the newly adopted smart grid are explored from the market design perspective to address its technological influence on a transformed society. With the help of technical innovation, it is likely that the historical industrial vision of Homeostatic Utility Control might come true, plausibly accelerating the evolution of electricity industry transformation. Consequently, it is very critical to take into account the impact of the smart grid for an efficient and well-structured commercialized electricity industry. The benefit of smart grid might be maximized only if technological efficiency is well coordinated and seamlessly incorporated with a global vision of energy sustainability.

\section{References}

[1] J. Jones, "Obama Signs Stimulus Packed with Clean Energy Provisions," The New York Times, 17 February 2009. [Online]. Available: http://www.nytimes.com.

[2] J. W. Hughes, and D. W. Von Dollen, "Developing an Integrated Energy and Communications Systems Architecture: The Initial Steps," in Proc. 2004 IEEE Power Systems Conference and Expositions (PSCE) Conf., pp.1651-1654, 2004.

[3] European Commission, "European SmartGrids Technology Platform: Vision and Strategy for Europe's Electricity Networks of the Future," ER Research Report EUR-22040, Brussels, Belgium, 2006. [Online]. Available: http://www.smartgrids.eu/.

[4] European Commission, "Strategic Research Agenda for Europe's Electricity Network of the Future," $E R$ Research Report EUR-22580, Brussels, Belgium, 2007.

[5] EU, "European SmartGrids Technology Platform," 2006.

[6] CSIRO, "Smart Grid Could Cut Emissions," Science Alert, 20 August. 2008. [Online].

Available: http://www.sciencealert.com.

[7] "Chinese Smart Grid Initiatives Launched," Metering. Com. [Online]. Available: http://www.metering.com.

[8] L. Schwartz, and R. Hodum, "Smart Energy Management for China's Transmission Grid," Renewable Energy World. [Online].

Available: http://www.renewableenergyworld.com.

[9] Iain MacGill, "EI Restructuring in Australia," 2005.

[10] Geoffrey Newman, "Power Cuts Loom as Financing Fails," The Australian, 13 July 2009. [Online]. Available: http://www.theaustralian.news.com.au/.

[11] H. Outhred, "The Smart Grid: Getting the Incentives Right," 2008.

[12] F. C. Schweppe, R. D. Tabors, J. L. Kirtley, H. R. Outhred, F. H. Pickel, and A. J. Cox, "Homeostatic Utility Control," IEEE Transaction on Power Apparatus and System, Vol.PAS-99, pp.1151-1163, May 1980.

[13] F. C. Schweppe, and H.R. Outhred, "Quality of Supplying for Electems," in Proc. IEEE Power Engineering Society Winter Meeting, 1980.

[14] Thomas Friedman, "Hot, Flat, and Crowded: Why We Need a Green Revolution--and How It Can Renew America," 2008.

[15] James G. Cupp, and Mike E. Beehler, "Implementing Smart Grid Communications," Technical Report of Burns and McDonnell, 2008. [Online]. Available: http://www.burnsmcd.com/.

[16] S. G. Kim, H. R. Outhred, and I. F. MacGill, "Commercializing Voltage Regulation in Electricity Spot Markets," International Energy Journal, Vol.6, No.1, 
part 2, pp.4-99 -108, June 2005.

[17] T. W. Berrie, "Electricity Economic and Planning," IEE, 2004.

[18] Lynne Kiesling, "Smart Policies for a Smart Grid: Enabling a Consumer-Oriented Transactive Network," [Online]. Available: http://www.hks.harvard. edu/hepg/Papers/2009/ Lynne_Kiesling_March09.pdf.

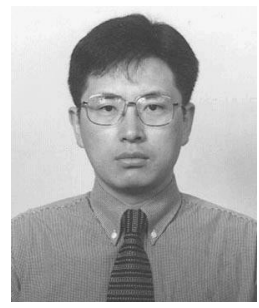

Seon Gu Kim received his Ph.D. in electrical engineering from the University of New South Wales in 2005. His research interests are electricity industry restructuring and grid integration of renewable energy, ancillary service markets, and optimization application to power system operation and planning. He has worked at KEPCO between 1991 and 2001. He has worked for the Korea Power Exchange (KPX) since 2001.

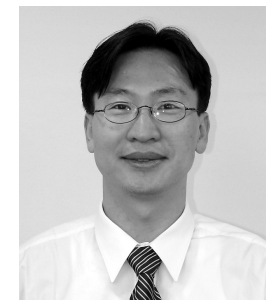

Seong Il Hur received his M.S. in electrical engineering from Korea University in 1995. His research interests are advanced tools and techniques for power system operation, analysis and planning. He worked at LS Industrial System Co. between 1995 and 2002. He has worked for the Korea Power Exchange (KPX) since 2006.

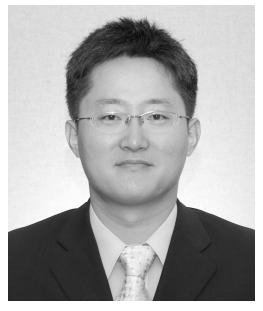

Yeoungjin Chae received his M.S. in Applied Econonomics for Electricty, Natural Gas and Telecommunication from Illinois State University in 2008. His research interests are the electricity economy, the electricity market and regulatory polices in the energy sector. He worked at KEPCO between 1996 and 2001. He has worked for the Korea Power Exchange (KPX) since 2001. 